\title{
Digital Threats to Democracy: Comparative Lessons and Possible Remedies
}

\author{
By Michael L. Miller (Social Science Research Council) and Cristian Vaccari (Loughborough \\ University) \\ Introductory chapter for the special issue of The International Journal of Press/Politics, 25(3).
}

We introduce a special issue that collects eight articles, comprising research from twenty-three countries and four continents on the sources, impact on citizens, and possible remedies to various digital threats to democracy, ranging from disinformation to hate speech to state interference with online freedoms. We set these contributions against the backdrop of a profound change in how scholars think about the implications of digital media for democracy. From the utopianism that prevailed from the 1990s until the early 2010s, the post-2016 reckoning has led to a change in the kinds of questions scholars ask, with the focus gradually shifting to investigations of the threats, rather than the benefits, of the internet. The eight contributions presented in this special issue employ a variety of disciplinary approaches and methods, often comparing different countries, to address some of the most pressing questions on how the internet can hinder the feasibility and well-functioning of democracy around the world. We conclude by setting out three challenges for future research on digital media and politics: a growing but still partial understanding of the extent and impact of the main digital threats to democracy; the risk that the dominant approaches become overly pessimistic, or founded on weak normative grounds; and the risk that research overemphasizes direct and short-term implications of digital threats on individuals and specific groups at the expense of indirect and medium-term effects on collective norms and expectations of behavior.

Keywords: democracy, digital media, disinformation, participation, comparative research

\section{Corresponding author}

Michael L. Miller, Senior Program Officer, Media \& Democracy, Social Science Research Council, 300 Cadman Plaza West, 15th Floor, Brooklyn, NY 11201, USA.

Email: miller@ssrc.org

\section{Author biographies}

Michael L. Miller is a Senior Program Officer in the Media \& Democracy program at the Social Science Research Council. His research focuses on the relationship between innovations in media technology and the balance of power between states and dissidents.

Cristian Vaccari is Professor of Political Communication, Co-Director of the Centre for Research in Communication and Culture at Loughborough University, and Editor-in-Chief of The International Journal of Press/Politics. His research focuses on political communication in comparative perspective. 


\section{Caught Off Guard}

This special issue of The International Journal of Press/Politics emerges out of a research development workshop convened by the Media \& Democracy program at the Social Science Research Council in June 2019, preceded and followed by open calls for papers. The workshop, titled "Digital Threats to Democracy: Comparative Lessons and Possible Remedies," was premised on the notion that many democracies around the world seemed unprepared to combat the threats related to digital media that have become all too common over the last decade. From surveillance to disinformation to coordinated hate and intimidation online, the once-heralded tools of digital liberation have been repurposed and redeployed in illiberal and antidemocratic ways that were, if not unimaginable, simply unimagined by many of the most prominent early theorists of digital politics.

For many observers, these threats seemed to culminate in the unanticipated electoral outcomes of 2016, which featured a US presidential election and a UK-wide referendum on the country's withdrawal from the European Union, colloquially known as Brexit. We now know that disinformation campaigns combined with the mass deployment of automated bots and trolls were coordinated with the purpose of interfering with democratic processes in each country (as discussed in this special issue by Golovchenko et al. 2020 with respect to Russian interference in US elections and by Tenove 2020 in terms of the policy responses to these threats to national sovereignty).

Yet those events may have been canaries in the coal mine. Since 2016, it has become clear that disinformation is not simply a foreign threat; that successful campaigns are waged by domestic purveyors of disinformation and, indeed, depend heavily for their success on networks of communication that include traditional media organizations, such as tabloid newspapers (Chadwick et al. 2018), radio stations, and cable news (Benkler, et al. 2018). Moreover, hate and toxicity are used by partisan activists and supporters to intimidate and silence political opponents in ways that disproportionately affect traditionally marginalized groups (Sobieraj 2019; Udupa 2020; see also Whitten-Woodring et al 2020 in this special issue). Mass electorates are increasingly concerned with the spread of misinformation and disinformation (as documented in this special issue by Koc-Michalska et al. 2020), to the point that many doubt whether news can be trusted, question whether truth can be discerned in public debate, or withdraw from the news altogether to stay out of trouble (Vaccari \& Chadwick 2020). This may have detrimental effects on satisfaction for democracy and belief in the legitimacy of this complex project (as highlighted in this special issue by Stoycheff 2020). And today, as the world reels amidst a global pandemic, the value of quality information has taken on new salience and the vulnerability of some sectors of our media ecosystems and of our societies have been exposed in unprecedented ways.

It has long been held that democracies cannot thrive in the absence of freely available and trustworthy information [Flynn et al. 2017]. Yet when lives are at stake and when every decision - every minute - matters, democracies depend on quality information, not simply to function well, but to function at all. And while the research presented here could not have foreseen the emergence of the COVID-19 pandemic, it nevertheless offers support for an emerging consensus within political communication: that perhaps the most significant threat to democracy around the world is the fact that flows of information, and the democratic quality of 
such flows, vary significantly by political and social context. Indeed, given the ubiquitous use of algorithms to personalize and micro-target content - from advertisements to music recommendations to search results - flows of information vary widely even from individual to individual. Moreover, it is increasingly evident that a few, entrenched quasi-monopolist corporations exercise unprecedented amounts of power on online information flows (Hindman 2018; Wu 2017) and that such flows are channeled, amplified, and augmented by interactions with organized political groups and traditional media, in complex ways unaccounted for in utopian visions of a free and open internet. In short, if perception is reality, democratic citizens may inhabit starkly different worlds, shaped in large part by the distinct information ecologies they engage with on a daily basis. And while contemporary news diets and experiences of politics may not necessarily be as fragmented and idiosyncratic as implied by the most pessimistic scenarios (as shown by Stier et al. 2020 in this special issue), some of the niche news ecosystems that have developed over the past few years raise concerns for democratic governance, which this special issue aims to address.

In what follows, we offer a necessarily cursory exegesis of the shift in narrative about digital media from tools of liberation to tools equally well suited to illiberal and anti-democratic ends. In short, it was once believed, not only that flows of information (or "speech") on the internet could not be controlled, but that it was precisely from this free flow of information that the liberating potential of digital media derived. Today, however, it is increasingly evident, not only that information is subject to control - by states and private actors alike - but that it is influenced by a variety of actors such that users may experience starkly different realities online depending on their identities, preferences, resources, and the social and political context surrounding them.

While our analysis will mostly focus on the technological and commercial development of the internet over the last thirty years, these transformations have also accompanied, and been accompanied by, relevant changes in democratic polities. Political actors and States have learned that the flow of information online can be shaped, at least in some spaces and among some groups, and the commercial development of social media platforms has provided them with a vast array of tools to achieve that goal. As digital advertising has grown in reach and precision, the ability to effectively communicate online has become increasingly tied to the availability of financial resources, especially in high-profile national campaigns. And while the internet has clearly helped challenger parties and candidates make a mark in electoral competition - from the Five Star Movement in Italy to Podemos in Spain, from Barack Obama in the United States to Emmanuel Macron in France - it has also empowered well-resourced outside actors, funded by nontransparent corporate or private interests, to acquire disproportionate visibility without corresponding accountability and responsibility. Moreover, evidence suggests that the financial crisis of 2007-8 and the long recession that accompanied it, together with the policy responses by most national and international institutions (Hacker \& Pierson 2010; Przeworski 2019), gave rise to a backlash against globalization and open societies that boosted the appeal of old and new authoritarian populists that have shown little respect, in words and deeds, for democratic norms and values such as separation of powers, the rule of law, and expertise (Norris \& Inglehart 2019). While digital media have often enabled political entrepreneurs of nativist anti-elitism - from Donald Trump in the US to Jair Bolsonaro in Brazil to Matteo Salvini in Italy - to bypass journalistic mediation to speak directly to their supporters, it is also the case that traditional media greatly contributed to their success (e.g. Wells et al. 2016; Boydstun \& Lawrence 2020). 
In sum, while politics is constantly fraught with conflicts and challenges - arguably, they are politics' very essence - the cleavages that have emerged in the present configuration of digital politics may be more complex, and more threatening to the democratic project, than in the recent past.

\section{Information Revolution}

Since its emergence in the 1960s and widespread adoption by the end of the 20th century and through to 2016, the dominant narrative about politics on the internet has revolved around a revolutionary imaginary. It was thought that the so-called "Information Revolution," brought about by the development of internet protocols and infrastructures, combined with advances in computer processing capacity, would transform passive consumers into the authors, curators, and publishers of mass-mediated content (Benkler 2006; Shirky 2009). This revolution promised new, "virtual" realities where people could recreate themselves outside the strictures of cultural norms, legal regulations, and political borders (Barlow 1995; Negroponte 1995; Castells 2007). This revolution heralded new ways of organizing social and political life that would shift power away from large, hierarchical organizations toward diffuse networks of autonomous individuals.

Despite such revolutionary rhetoric, the internet originated within the halls of the Defense Advanced Research Projects Agency (DARPA) of the United States Department of Defense, and its purpose was to provide the US military with a communications infrastructure capable of withstanding a coordinated nuclear attack. A feature of the internet's design known as the endto-end principle dictates that functionality on the network reside in the computers that connect to the network, not in the network itself. In other words, the technical capacity to produce, store, and distribute data is held by computers, and the internet itself is neutral, a latticework of "dumb tubes" that are exclusively concerned with transmitting information as efficiently as possible by following routing commands. Crucially, this distribution technology is unconcerned with the content of that information, or the physical location or identities of end users (either the client requesting information or the server hosting it).

Moreover, information is distributed on the internet via a process called "packet switching," in which data are broken up into smaller pieces and sent separately to their destinations, where they are reassembled as interpretable forms of information: images, audio files, or documents, for example. Packet-switching protocols determine that if any node in the network is destroyed or impaired, packets of data will still make their ways to their destinations: the network will simply reroute them along any number of alternative paths.

In theory, the end-to-end principle in combination with packet switching protocols engender a decentralized or distributed network, in which it would be impossible to disrupt communication on the network simply by destroying one or several centralized nodes in the network (Baran 1962; Galloway 2004). And while it is easy to understand how such a distributed infrastructure might seem advantageous from a military-defense point of view, its broader social and political implications were less straightforward. Nevertheless, as this infrastructure was privatized and made available for commercial use, its revolutionary potential began to be theorized by the 
narrow groups of scholars, computer programmers, and hobbyists who had been influential in its development or in its early adoption for popular use.

Importantly, many early theories of digital politics assumed that the same technical features that would shield the internet from attack would also limit — even obliterate - the capacity of governments to control flows of information through the network (Johnson and Post 1996; Barlow 1996; Negroponte 1995; Shapiro 1999). Insofar as the network was resistant to centralized attack or disruption, it would also be immune to centralized control or management. If the network remained neutral, data sharing on it would remain autonomous and it would be impossible for states or other centralized actors to interfere with free expression in this sphere of social life.

If the internet was fundamentally resistant to control, collective decisions would have to be made by alternative means, thus ushering in an alternative model of governance. It was argued that liberal and anti-hierarchical values were embedded in the very protocols that defined how computers must operate on the network - even in the mechanisms by which protocols were designed and implemented. Problems of the internet would not be resolved by ballot or by edict, but by mechanisms of consensus among interested parties — chief among them computer programmers. According to John Perry Barlow, this was because solutions on the internet must win "by virtue of adoption, and they don't get adopted if they're bad solutions" (Barlow 2000). Summarizing this value system, one of the internet's architects stated, "We reject: kings, presidents, and voting. We believe in: rough consensus and running code" (Clark 1992).

Such was the prevalent view of many early theorists of the political internet: that the technical features of the communication infrastructure would necessarily militate against centralized control; that this function would inevitably create opportunities for free expression; and that these opportunities were necessarily conducive to political liberation. These were decidedly normative - indeed, utopian - theories, with strong influences from the American strand of liberalism known as libertarianism. It is notable, moreover, that despite the many contributions of non-white and non-male scientists, hobbyists, and early adopters of internet-based technologies, the utopian-libertarian strands of early internet political theory were disproportionately concocted by white, Anglophone men (McIlwain 2019).

By the turn of the new millennium, utopian theories were still dominant, and even refined. Fast expanding access to internet connections and increasingly affordable personal computing capacity were deemed to further augment the liberating potential of free-flowing information. Such capacity would give voice to otherwise marginalized political voices, enabling them to circumvent the gatekeepers of traditional media (Drezner and Farrell 2004). Far from being drowned out in a cacophony of competing voices, individual end users would leverage the emerging constellation of online social networking sites to express themselves and connect with each other in new, potentially disruptive, but fertile and empowering ways. The "information exuberance" (Chadwick 2009) that would result from this free flow of interactions and exchanges was generally seen as a breath of fresh air from an elite-controlled political communication system increasingly absorbed in cycles of spin and counter-spin between journalists and campaign professionals, crowding out ordinary citizens' agency and engagement (Entman 1990; Patterson 1994; Gurevitch \& Blumler 1995). With Wikipedia as the archetype, 
digital utopians argued that we no longer had to choose between the elite and the masses: we could choose both. We could leverage the capacity of citizens to create open, accessible cultural and economic products of superior quality than their analogue counterparts (Tapscott \& Williams 2006; Benkler 2006). We could harness the ability of activists to organize movements that would be nimble, inclusive, and could scale more quickly than traditional organizations (Rheingohld 2002; Surowiecki 2004; Shirky 2009; Bennett \& Segerberg 2013). We could build new online commons that would enable citizens to express themselves, engage with causes they cared about, and meaningfully contribute to democratic self-governance even if they could not devote vast amounts of time and resources to these endeavors (Blumler \& Coleman 2009).

It is important to note that the utopian visions of much early writing on the internet and politics did not go unchallenged in social science research. From the early days of digital politics research, supporters of what came to be known as the "normalization" hypothesis (Margolis \& Resnick 2000) argued that the internet was not going to fundamentally transform key aspects of politics. Even more nuanced empirical analyses of the limits of the transformative potential of the internet emerged at the turn of the millennium, focusing on its tendency towards concentration of power (Hindman 2008), the limited effects of the democratization of information it enables (Bimber 2003), its ability to magnify rather than reduce political inequalities (Bimber and Davis 2003), its limited capacity to foster coherent, inclusive, and transformative public dialogue (Papacharissi 2002), the reluctance among political parties to embrace its participatory potential (Gibson et al. 2003) and the risk that politicians would use digital tools to collect unprecedented amounts of individual-level data that would enable them to segment, manipulate, and disempower citizens (Howard 2006). Nuanced reviews of the field of digital politics emphasized the need to strike the right balance between technological determinism - ascribing inherently transformative and societally beneficial powers to the internet - and social constructivism - highlighting the role of long-term social structure and power imbalances in shaping any implications of technology (Chadwick 2006). It is fair to say that most scholars who set out to study the relationship between the internet and politics from the 1990s onwards did not uncritically share most of the utopian predictions of the theorists whose ideas we have briefly summarized here. Still, most empirical research - including our own (Vaccari 2013) - started from the argumentative premise that the internet could indeed have a democratically-enhancing transformative potential and that the possibility of such potential deserved empirical scrutiny, if only to circumscribe them, contextualize them, and identify the conditions under which they were more and less likely to materialize. In other words, the utopian techno-optimism of the first wave of digital politics theories did not shape the results of academic research, but it definitely informed the questions scholars set out to answer and the (often implicit) normative frameworks based on which they interpreted their findings.

\section{Information Reaction}

With a zeal that would seem out of place today, and an unwitting signal that digital utopianism had reached its peak, Clay Shirky titled his 2009 book Here Comes Everybody. Even more revealing is the book's subtitle-How Change Happens When People Come Together. As the internet developed, the amount of people who can come together and the reasons why they come together has continued to increase. In hindsight, we may have gotten more than we bargained for. 
The so-called "Arab Spring" of 2011 seemed to confirm the digital utopian thesis that popular sovereignty would be enabled by digital tools of connectivity and access, streamlined by thenascendant social media platforms. But even as revolutions in the Middle East and North Africa toppled dictatorships, and as scholars embarked on a contested debate on the extent to which digital media had really contributed to these revolutions (Howard 2010; Tufekci \& Wilson 2012; Wolfsfeld et al. 2013), elsewhere in the world the story was quite different. Indeed, at the close of the first decade of the new millennium, the same technologies that briefly liberated citizens in Egypt and Tunisia were being deployed in novel ways to surveil and repress dissidents in authoritarian regimes such as China and Iran (Diamond 2012).

The first cracks in digital utopianism started to appear. In the first case, access, so fundamental to the utopian thesis, was shown to be unevenly distributed. Not only was access not nearly as extensive outside of the wealthy capitalist democracies of the West, but even within these countries, it varied significantly by demographic characteristics such as age, race, gender, and education (Norris 2001). Even as the divide in access narrowed, scholars identified persistent inequalities in both technological skills and media literacy (DiMaggio et al. 2004; Van Dijk 2005; Hargittai \& Shaw 2013). As an example, research has found that most disinformation in the 2016 US Presidential election was spread by older conservative voters (Guess et al. 2019) precisely the kinds of users who were less likely to use the internet in the early stages of its mass diffusion (Hindman 2005). As research by Pennycook and Rand (2019) has shown, users who employ simple, "lazy" styles of thinking are more likely to believe online disinformation than those whose cognitive styles are more systematic and "analytical". To the extent that the internet has become increasingly dominated by platforms whose user-friendly interfaces are constantly refined to keep their users entertained, engaged, and glued to their screens, it seems to be more conducive to "lazy" thinking than the more cumbersome and self-directed "information superhighway" of yesteryear. And as smartphones with mobile broadband have further democratized access to the internet, especially in poorer countries and among sectors of the population without personal computers, it has become apparent that smartphone screens are not ideally suited to consume complex content such as news (Dunaway \& Soroka, 2019). While these may be fair prices to be paid for a more socially inclusive digital ecosystem, these were arguably not prices that were fully anticipated, nor accounted for, in early discussions of the digital divide. Moreover, as critical race scholars have demonstrated, when different groups go online, they often utilize new media technologies in ways that early adopters had not-indeed, could not have - anticipated (Brock 2012; Steele 2016; Steel 2017). Thus, as the cohort of early technological adopters was progressively outnumbered online by a larger and more diverse population of newer digital citizens, the online marketplace of ideas has arguably become more complex and even chaotic, complicating not only the story of the internet as a space of universal access, but also the simple dichotomy of internet haves and have nots.

However, the more fundamental critique of the utopian consensus was that, contrary to popular belief, control of end user experience and behavior on the internet was not only quite possible, but could be managed in ways that went beyond maintenance of the status quo, and actually enhanced state capacity to surveil and repress dissent (Goldsmith and Wu 2006; Morozov 2011). In many ways, utopian hubris about the liberating effects of digital media reflected a UScentered modernist meta-narrative about technological progress. Perhaps it is not surprising then, 
that the most damning critiques of the utopian liberation technology thesis emerged from scholars who studied digital politics in settings where liberal democratic norms could not be taken for granted.

In many authoritarian regimes, for example, states were so central to the adoption and expansion of internet infrastructures that they could ensure these technologies ultimately served statedefined priorities, even as some digital affordances enabled limited challenges to state authority (Kalathil and Boas 2003). In fact, information controls evolved a great deal over the decade that culminated in the Arab Spring. While "first and second generation controls" worked by blocking or filtering content through technical, legal, or regulatory mechanisms, "third generation controls" focused less on denying access to internet resources and more on waging propaganda and counter-information campaigns, as well as using surveillance as a means to create cultures of fear that would discredit, demoralize, and overwhelm opponents (Deibert, et al. 2008, 2010, 2012). In an illuminating analysis of how the Chinese state domesticated the internet and turned it into a tool of state control, Roberts (2018) identifies three types of censorship - "fear," deterring people from speaking their minds by threatening sanctions; "friction," making it hard for people's voice to be heard by manipulating, or temporarily stopping, the flow of information; and "flooding," or drowning out dissent with an avalanche of content focused on entertainment, lifestyle, and feel-good news. The "social credit system" that is being rolled out by the Chinese government is poised to dramatically extend state control over citizens' lives by connecting digital trace data on their online activities — chief among them political self-expression — with a system of rewards and punishments discriminating access to fundamental public services and opportunities (Liang 2018). This would entail a full-blown reversal of the original utopia of the internet as an inherently anarchic and libertarian force, putting it at the service of a pervasive project of authoritarian social control instead.

Yet despite an emerging consensus that governments could, in fact, deny access to- or otherwise disrupt flows of-Information online, to many at the end of the first decade of the new millennium, the antidemocratic and illiberal threats of digital media still appeared as nonWestern and non-democratic phenomena (Deibert, et al. 2012; Diamond 2012). If there were threats to democracy borne of digital media, they were distinctly authoritarian threatschallenging democracy's emergence, not its survival where it had long since taken root.

The first clue, or perhaps the first publicly visible sign, that digital threats to democracy might be homegrown in the West as well, was the 2013 Guardian scoop that exposed the US National Security Agency (NSA) and the British Government Communications Headquarters (GCHQ) mass surveillance programs (Greenwald 2013). The scandal unveiled by NSA contractor Edward Snowden revealed that the US and UK governments had not only the technical wherewithal but also the will to conduct dragnet surveillance of their own citizens (Geiger 2018). Moreover, the investigation closed the door rather tightly on optimistic takes on digital politics that assumed the individual liberty-enhancing qualities of digital media. Indeed, even within the field of surveillance studies, which was already disposed to more critical analyses of technology in society, the Snowden revelations represented a critical juncture, such that the field has been described in terms of "before" and "after Snowden" (Lyon 2015). 
If the first clue signaled a threat to the individual liberties of democratic citizens, the second signaled an intrusion on their popular sovereignty. In 2016, citizens in the West became aware, all at once it seemed, of coordinated disinformation campaigns seeking to disrupt the US presidential election and the UK referendum on exiting the European Union. It is now known that agencies and operatives acting at the behest of the Russian government conducted largescale propaganda campaigns, including the purchase of advertisements on major social media platforms and the mobilization of an army of bots and trolls, each seeking above all to sow mistrust and discord among citizens in two of the world's oldest democracies (Howard, et al. 2018; DiResta, et al. 2018; Jamieson 2019; Golovchenko et al. 2020 in this special issue). While most scholars are skeptical that these efforts were enough, per se, to sway the outcome of these elections, the fact that these efforts were even possible on a large scale, often with the unwilling complicity of domestic news media (Lukito et al. 2020) and self-interested domestic politicians (Giglietto et al. 2019) contributed to dismantling the useful democratic myth of the "attentive public" (Karpf 2019). This is the idea that mass electorates, while incapable of and uninterested in constantly and closely scrutinizing politics, can be expected to see through blatant and pervasive acts of mass deception, and defend themselves from them at the voting booth (Lupia \& McCubbins 1998; Erikson et al. 2002). Whether this state of affairs is empirically true or not (Achen \& Bartels, 2017), one of the bedrocks sustaining the legitimacy of democratic government is that the public is capable of ultimately discerning what is good for itself and that self-interested politicians have only limited ability to elude voters' vigilance. As Abraham Lincoln - or possibly P.J. Barnum - once said, "You can fool some of the people all of the time, and all of the people some of the time, but you cannot fool all of the people all of the time" (Vaccari 2019). Another myth that 2016 contributed to shattering is what Hedrick and colleagues (2018) call the "earnest internet", or the idea that most people can be trusted to mean well and behave fairly and honestly when they are online. This arguably naïve idea, which nonetheless informed decades of theories and prophecies around the wisdom of the crowds, the gift economy, and the self-correcting capabilities of distributed networks, just to name a few, has given way to concerns about a new "culture of indeterminacy" (Chadwick 2019) fueled by the widespread assumption that little of what is shared online can be trusted and, hence, that individuals have little agency, let alone responsibility, for improving the quality of public communication on the internet (Vaccari \& Chadwick 2020).

Taken together, these two signs - one, an intrusion on the privacy of democratic citizens; the other, an intrusion on democratic citizens' ability to make free electoral decisions - put to rest the libertarian-utopian notion, once the consensus view among scholars and commentators in the US and across most of the West, that digital media were necessarily tools of liberation.

Moreover, they compelled Western scholars to take seriously the notion that inasmuch as digital media might be boons to the twin pillars of Western democracy - individual liberty and popular sovereignty - they might also threaten them, whether directly, by impeding the processes they require, or indirectly, by diminishing their legitimacy among the public and weakening the social norms that make democracy possible in the first place.

Today, scholars such as Bimber and Gil de Zúñiga (forthcoming) and Bennett and Pfetsch (2018) refer to an "unedited" or "disrupted" public sphere, in which some forms of speech that enrich democracy have been strengthened, even as antiliberal forms of speech, such trolling, harassment, and expressions of hate make online discussion spaces inhospitable or unsafe 
(Phillips 2015; Boatright et al. 2019). Indeed, precisely because gatekeeping power has been redistributed (but not necessarily democratized), digital media users are freer than in the past to consume, produce and distribute misleading, polarizing, or speech-suppressing content. What is more, organized political actors - both inside and outside the system of legitimate democratic representation - have become increasingly capable of harnessing and channeling bottom-up efforts by online activists, which can scale up to substantial coordinated campaigns amplifying elite messages (Zhang et al. 2018; Giglietto et al. 2020). Parties and candidates have also been enabled to reach susceptible groups by using sophisticated but nontransparent digital advertising tools that tech platforms developed to maximize their profits and with an eye to the consumer market, often without putting much thought into what would happen were the same tools to be deployed to influence democratic elections and decisions (Wu 2017; Vaidhyanathan 2018; Zuboff 2019).

The result is that today we may inhabit wildly different information environments and that these communication microclimates are increasingly shaped by well-resourced organized political actors and their partisan supporters, as well as by digital platforms' commercial imperatives, rather than by a genuinely free flow of ideas and information — or, for that matter, a flow organized according to widely agreed-upon norms of democratic citizenship. In short, and in contrast with the first generation of digital politics research, scholars are increasingly aware that some aspects and uses of the internet may threaten key features of democracy — as a project, as a possibility, and as a system of government.

\section{Clarifying Challenges, Assessing Solutions: This Special Issue}

Against this backdrop, scholars of media, technology, and politics have a key role to play in asking and answering empirical questions about the extent and causes of digital threats to democracy, and in evaluating the potential costs and benefits of different remedies. The need to empirically address these challenges also reveals the limitations of some of the normative underpinnings on which research in political communication, and digital media and politics in particular, has rested so far (Bucy \& D’Angelo 2004; Strömbäck 2005; Chadwick 2019). Faced with the concrete possibility that the current configuration of the affordances of digital media may exacerbate certain long-standing threats to democracy, and given the delicate balance between the need to protect societies from these threats and the risk of limiting fundamental rights such as freedom of expression, researchers have the right and the duty to contribute knowledge and ideas to a public debate that is often fraught with short attention spans by the public, indulgence to simplification by journalists, facile posturing by politicians, hasty solutionism by policymakers, and prevarication by tech companies (Nash 2019; Tromble \& McGregor 2019; see Tenove 2020 in this special issue for a review of existing policy responses).

In this context, our call for papers asked international scholars from different disciplines to reflect and shed light on the challenges that digital media pose to democratic institutions and processes. What lessons might be learned from the different experiences of polities around the world, including nondemocratic ones, that have been facing digital threats to democracy for longer than their counterparts in Europe and the United States? How do such threats manifest in different political settings and are there generalizable insights about the downsides of digital 
media in democratic contexts? What do we know about the ways in which these threats can be tackled, and their most pernicious implications reduced?

The research collected in this issue suggests that one of - if not the - greatest digital threat to democracy derives from precisely the same mechanism that was previously expected to liberate the minds of anyone with access to an internet connection and computing capacity. The free flow of information online has meant that anyone and everyone-be they independent learner, civicminded activist, voter, agent provocateur, or bot-has some capacity to shape communication and, in turn, knowledge, public opinion, and social behavior. But just as does money in an economic market, unregulated flows of information get concentrated in ways that yield distinct advantages, even quasi-monopolies, to certain organizations, groups and actors over others, and a digital divide - again, if not in access to resources, certainly in skills, literacy and, ultimately, influence and power-looms large as a result. Traditional theories often assumed that an open internet would necessarily result, not only in better informed users, but in societal consensus through the seamless real-time aggregation of individual contributions treated equally and evaluated solely based on their merits, as evidenced by support gathered among other users. Instead, in many instances digital media have facilitated the spread of misinformation and disinformation, or of opinionated content that, albeit not blatantly false, contribute to ongoing processes of social and political polarization and fragmentation, as well as distorting the aggregation of interests and preferences.

The eight contributions collected in this special issue advance our understanding of some potential sources of digital threats to democracy, of how citizens are affected by and may contribute to these threats, and of some possible solutions to these problems. These studies combine a variety of disciplinary perspectives - political science, media and communication, and sociology - and employ a variety of methods - computational analysis, in-depth interviews, focus groups, surveys, analysis of secondary data, and policy analysis - often combining multiple approaches and comparing different countries. The articles cover twenty-three countries in four different continents, including established Western democracies (Australia, Austria, Belgium, Canada, Denmark, Finland, France, Germany, Greece, Ireland, Italy, the Netherlands, Norway, Portugal, Spain, Sweden, Switzerland, the United Kingdom, and the United States), a younger, and arguably backsliding, Eastern European democracy (Poland), an East Asian democracy (Taiwan), and two authoritarian regimes (Myanmar and Russia). Below, we provide short summaries of each contribution.

\section{Sources of Digital Threats}

Covert foreign propaganda on social media threatens electoral integrity and democratic sovereignty. Relying on a unique research design that combines computational and human analysis of Twitter and YouTube, Golovchenko and colleagues (2020) investigate the activities and reconstruct the strategy of Russian Internet Research Agency (IRA) "trolls" during the 2016 United States Presidential election. Combining theories of propaganda and insights from ongoing debates among the US intelligence community, the authors develop two alternative (albeit not necessarily mutually exclusive) hypotheses regarding the goals of Russian interference in 2016: to support Donald Trump or to sow discord by spreading polarizing messages on both sides of 
the political spectrum. The findings suggest that while Twitter IRA trolls spread both conservative and liberal content, conservative accounts were more active and most of the YouTube videos they shared on Twitter were conservative, hence lending more support to the hypothesis that the IRA worked to support Trump's election. This research shows that foreign propaganda networks can be nimble and internally differentiated and highlights the importance of studying the whole online ecosystem of propaganda, going beyond single-platform case studies. While issues of data access and comparability make this a very complex task, Golovchenko and colleagues show that this is both possible and fruitful.

Russia and the United States are also the focus of Stoycheff's (2020) contribution, which addresses another potential source of democratic threats - the state itself, insofar as it engages in online mass surveillance and restricts the free flow of information on the internet. Stoycheff investigates how citizens' perceptions of state interference with internet freedom predict the extent to which, and the democratic implications of, citizens' engagement in what she terms "deliberative internet use", defined following Bailard (2014) as the combination of "mirror holding" (seeking critical information on government) and "window opening" (consulting global metrics to assess government's performance). Among survey respondents in both Russia and the US, survey respondents, belief that government interferes with internet freedom is positively associated with deliberative internet use and negatively associated with satisfaction with the way democracy works. However, Stoycheff highlights two key differences between the two countries. First, Americans are more concerned about their government's online interference than Russians. Secondly, the ways in which these concerns translate into deliberative internet use and attitudes towards democracy diverge. For Russian respondents, perceptions that their government threatens internet freedom increase deliberative internet use, which in turn decreases specific satisfaction for their own democracy but increases generic support for democratic rules and procedures. These patterns support the theory of "relative deprivation", according to which citizens increase their support for democracy when they believe their country is worse governed than others. By contrast, among US respondents, awareness of state interference with internet freedom increases information-seeking online, but this in turn does not translate into lower levels of specific satisfaction for American democracy; instead, general support for democracy was reduced. These findings provide cause for both concern and optimism. On the one hand, citizens are alert to their governments' interference with internet freedom and can find information on the internet itself to monitor state activity. On the other hand, increased awareness and engagement with online monitoring of government performance lead to a greater appetite for democracy among citizens who live in an authoritarian regime than among those who live in an (imperfect but still functioning) democracy.

The use of digital media by organized groups and ordinary citizens to spread hate speech is another potential threat to democracy. The complex relationship between digital media and human rights is the subject of Whitten-Woodring and colleagues' (2020) contribution, which focuses on Myanmar. The authors conducted in-depth interviews and focus groups to understand news consumption and social media use patterns in a country marred by genocide and where Facebook played a controversial role in enabling hate speech against Rohingya Muslim minorities. The data highlight that Facebook is a very important source of information for Myanmar citizens, who see news on the platform as less censored and more sensitive to local issues than news in the mass media. The interviews also reveal that Facebook played a somewhat 
two-faced role in the Rohingya genocide - enabling those who wanted to report the atrocities to circumvent government censorship but also serving as a vehicle through which various groups spread hate speech against the Muslim minority. Whitten-Woodring et al. (2020) highlight relevant differences between Facebook users and non-users. Those who use Facebook are exposed to a greater variety of news sources, which sometimes makes it difficult to decide what to believe but is mostly interpreted in accordance with one's preexisting views. By contrast, nonusers mostly rely on domestic or government sources, which tend to be hostile to the Rohingya. Common among both groups of interviewees was a general distrust of international news media, accused of being partial in favor of the victims of the genocide. This nuanced study in a crucial but under-researched country highlights that in those authoritarian regimes where news organizations are less developed and trusted, the role of digital media-including the threats they may contribute to - can be even more crucial than in established democracies.

\section{Citizens as Targets of, and Contributors to, Digital Threats}

The increasing diversity and complexity of contemporary information flows enhance citizens' choices and opportunities, thus increasing the relevance of how and where they decide to acquire news, how they interpret its contents, what resources they bring to bear in assessing its quality and truthfulness, and whether and how they share it with others. Since citizens tend to choose sources that are congruent with their political preferences, and since the rise of populism has been identified as a potential challenge to liberal democracy, understanding the news diets of populist voters can shed light on the ways in which the internet may have helped create a fertile breeding ground for populist ideas. To shed light on these issues, Stier and colleagues (2020) combine web tracking and survey data in five European democracies and the United States. They find that citizens with populist attitudes consume news from a variety of online sources and do not necessarily avoid public service media, even though many populist leaders have directly challenged and lambasted these outlets. What mostly differentiates populist citizens from the rest of the population, however, is their higher reliance on hyper-partisan websites (such as Breitbart News) and their lower propensity to visit legacy press websites. Still, most respondents, even among those with populist attitudes, visit more legacy press sites than hyper-partisan sites, and while tabloid newspapers have often championed some of the themes and espoused the rhetoric of authoritarian populists, the relationship between populist attitudes and exposure to tabloids is actually negative in Germany and Italy and not significant in all the other countries-including the UK where tabloids are most popular. Overall, Stier and colleagues' (2020) study shows that populist citizens are taking advantage of the selective affordances of the internet to consume more of the polarizing content that may confirm their worldviews. However, populist voters' news diets also include substantial engagement with traditional journalistic content, especially from television and digital-native outlets, which suggests that anxieties for the fragmentation and polarization of contemporary news ecosystems may be overstated.

Another paramount concern regarding citizens in the digital age is the extent to which they encounter, react to, and correct misinformation and disinformation. While these issues have dominated public and scholarly debates since 2016, research on the extent and sources of the problem has yielded conflicting results. Koc-Michalska and colleagues' (2020) contribution sheds light on this topic based on surveys in France, the UK, and the US. Discussion of news, 
use of social media for political purposes, and exposure to counter-attitudinal information consistently predict reported exposure to false information across all three countries. Besides these commonalities, the US clearly stands out in comparison with the UK and France for three reasons. First, US respondents are substantially more likely to claim they were exposed to falsehoods than French and British respondents. Second, voters for Donald Trump are more likely to report encountering false information, in contrast with voters for right-wing parties and candidates in France and the UK. Third, Trump voters are more confident in their own ability to identify misinformation as untrue on its face (as opposed to relying on contextual cues such as an unfamiliar source or the presence of spelling and grammatical errors). Koc-Michalska and colleagues' (2020) study thus suggests that Trump largely succeeded in his campaign to sow distrust in the news in ways that his counterparts in France and the UK had not yet accomplished, at least by 2017 when the data were collected.

Fact-checking is often hailed as one potential solution to the problem of misinformation and disinformation. However, to the extent that trust in expertise and professional news becomes a divisive political issue (Waisbord 2018), citizens of different political persuasions may not be equally convinced of the value of fact-checking. Lyons and colleagues (2020) address this topic based on surveys in six European democracies. They show that most respondents are not familiar with the fact-checking movement in journalism but are generally favorable towards it. However, awareness and appreciation of fact-checking by and large depend on a citizen's political attitudes. In particular, interest in politics predicts familiarity with fact-checking and satisfaction for democracy predicts both familiarity with and favorability towards fact-checking. Taken together, these findings suggest that fact-checking is failing to reach precisely those politically uninterested and disaffected citizens that are arguably most vulnerable to misinformation and disinformation. Moreover, there are clear signs that political cleavages similar to those identified by previous research in the United States (Robertson et al. 2020) shape attitudes towards factchecking in Europe as well. In most countries, satisfaction with the European Union is positively associated with favorability towards fact-checking. There is also evidence that voters espousing conservative ideologies view fact-checking less favorably, while supporters of Socialist and Green parties tend to have more favorable views. Overall, this study suggests that fact-checking alone is unlikely to mitigate the problem of disinformation - not because of any shortcomings in the work of fact-checkers themselves, but because of their uneven reach and support among different groups of the population. It is what citizens think about - and do with - fact-checking that shapes the conditions for its success or, as Lyons et al.'s (2020) study suggests, lack thereof. If this is true, solutions to the threat of misinformation and disinformation are likely to require more systemic approaches, especially ones that tackle the deeper roots of the problem.

\section{Protecting Democracies from Digital Threats}

The last two articles in this special issue focus on possible defenses against, and solutions to, the threat of disinformation, addressing institutional and societal characteristics, on the one hand, and policy responses, on the other.

Humprecht and colleagues (2020) start from the premise that in the current media environment it is inevitable that certain actors will circulate, and various citizens will see, some disinformation 
some of the time. The key challenge for democracies is thus to minimize the negative effects of this threat by developing resilience, defined as a collective rather than individual characteristic that equips a country - or a community within a country - to withstand this challenge. Humprecht and colleagues theorize that different systemic factors can weaken such resilience: the political environment (specifically, high levels of societal polarization and the success of populist political actors), the media environment (low trust in news, weak public service media, and high audience fragmentation), and the economic environment (large size of the digital advertising market and high levels of social media use). The authors then operationalize these concepts by combining a variety of datasets and estimate resilience to disinformation across eighteen Western democracies. The results show considerable variation in estimated resilience to disinformation across these countries, suggesting that the problem should be diagnosed and tackled based on a careful examination of the context where it occurs. The United States is unique in its lack of resilience to disinformation, largely due to three characteristics: high levels of audience fragmentation, weak public service media, and a large digital advertising market. A second group of countries that exhibit comparatively low levels of resilience includes Mediterranean European countries, where low levels of trust in media, high levels of social media use, and widespread populist attitudes expose society to the threat of disinformation. Finally, Northern European countries and non-US Anglo-Saxon countries with strong public service media turn out to be the most resilient against disinformation. Humprecht et al.'s (2020) study provides a platform for comparative scholars interested in assessing the causes and effects of the spread of disinformation, as well as highlighting that the seriousness of this digital threat varies considerably across democracies. While some of these factors are rooted in historical and political economy dynamics outside the direct sphere of influence of the state, some, such as the strength of public service media, can be addressed by deliberate policy choices.

This is the theme of Tenove's (2020) policy analysis of responses to disinformation across ten countries and the European Union. Policy choices are largely shaped by how a problem is defined, and online disinformation is no exception. When the decision-makers define disinformation as a threat to self-determination in free democratic elections, the main response involves international and national security policies, such as cyber-security, cyber-warfare, and counter-information operations. When disinformation is presented as a threat to accountable representation, policy responses revolve around the regulation of campaigns and elections, including norms imposing sanctions for the spread of disinformation online, updating campaign finance laws to incorporate digital expenditures, and enhancing transparency in online political advertising. Finally, when disinformation is framed as a threat to the quality of public discourse, the main policy responses entail media regulation, particularly targeting how social media companies deal with different kinds of illegal or legal but problematic content. Tenove's (2020) analysis is helpful both as a conceptual map and heuristic device for researchers and as an inventory of different approaches and options for policymakers-including the different risks and trade-offs they entail.

\section{Moving Forward}

We hope this special issue will contribute to and inspire the work of researchers, practitioners, digital media companies, and policymakers around the world who care about democracy and are 
concerned about threats to its functioning — and even its existence - that have emerged out of largely unforeseen, but not unimaginable, developments in the functioning of the internet and the ways in which different types of actors employ digital affordances to achieve political goals.

While no collection of articles can shed enough light on challenges so diverse, complex, evolving, and context-dependent, the studies included in this special issue highlight the benefits of research that is international, interdisciplinary, multi-method, and multi-platform. As we trust readers will agree after engaging with the contributions presented here, our knowledge is rapidly growing in breadth and depth. Nevertheless, many challenges lie ahead for those who aim to better understand and mitigate digital threats to democracy. We highlight three that we think are particularly relevant.

First, our understanding of the problem is still partial. For one, most ongoing research on digital threats to democracy has focused on disinformation, as this special issue itself testifies. While this is definitely an important challenge, it is not the only one worth considering. Hate speech and intolerance, mass surveillance, censorship, and perverse uses of microtargeting, just to name a few, are equally as troubling. We also do not know enough about how these phenomena unfold beyond high-profile moments such as elections, in private as well as public and semi-public channels of online communication, and outside of Western democracies. And while we have developed some useful knowledge of how politicians, journalists, and citizens are navigating, and sometimes contributing to or even taking advantage of, these challenges, we do not know nearly enough about how digital media companies make decisions - from grand strategies to temporary experimentations - that dramatically shape the context in which we communicate about public affairs.

Secondly, there is the danger that the pendulum has swung, or will swing, too far too fast towards digital pessimism. A renewed focus on the democratic challenges that the internet has brought about should not distract us from the opportunities it continues to provide. There is no golden age of mass mediated political communication that we should yearn for, as entire library stacks of scholarship critical of mass media's contribution to democracy testify. Scholars will need to answer pressing normative and empirical questions on how contemporary media ecosystems contribute to democracy, without any bias in favor of optimistic or pessimistic narratives. Research on incivility in online political talk offers an illustrative example of a journey in the opposite direction to that currently taken by scholars of disinformation and other digital threats. While early studies considered most, if not all, forms of online incivility as inherently problematic for democracy (Mabry, 1997; Ng \& Detenber, 2005), contemporary research has developed more nuanced conceptualizations of different types of antinormative online political talk, leading not only to more precise empirical measurements of a complex constellation of phenomena, but also to more refined, and overall less pessimistic, normative assessments of their contributions to democracy (Papacharissi 2004; Masullo Chen et al, 2019; Rossini, forthcoming). It is too early to tell whether the currently burgeoning field of online disinformation will follow a similar path as scholars continue polishing their concepts, measurements, and underlying normative models, but the possibility should not be ruled out.

Thirdly, the long-term and indirect collective implications of digital threats to democracy require as much, if not more, attention than their short-term and direct individual effects. For instance, 
while it is important to know how many people are directly exposed to and affected by disinformation or hate speech, it is just as important to understand whether the sustained public debates and news coverage around these problems may affect citizens' attitudes and behaviors in the long run. Does discussion of digital threats to democracy risk exacerbating some of these problems by further eroding trust in other citizens, in the news, and in the viability of the democratic project of self-governance itself? How are the norms and expectations around what it means to be a producer, consumer, and distributor of publicly relevant information changing as a result of the negative climate of opinion around online political debate, and how are those developments affecting the ways in which individuals and groups behave politically? And how does the potential weakening of democratic communicative norms shape users' behavior during exceptional moments, such as contested high-profile elections, constitutional crises, eruptions of social conflict, and public health emergencies such as the COVID-19 pandemic that looms large as we finalize this special issue?

We trust that these and other questions will keep our research communities occupied and engaged in lively, difficult, and important debates for the next few years. We hope this special issue can play a small part in this collective endeavor.

\section{References}

Achen, C. H., \& Bartels, L. M. (2017). Democracy for realists: Why elections do not produce responsive government (Vol. 4). Princeton University Press.

Bailard, C. S. 2014. Democracy's Double-Edged Sword: How Internet Use Changes Citizens' Views of Their Government. Baltimore: Johns Hopkins University Press.

Baran, P. (1962). On Distributed Communications Networks: RAND Corporation. https://www.rand.org/pubs/papers/P2626.html

Barlow, J. P. (1996, February 8). A Declaration of the Independence of Cyberspace. https://www.eff.org/cyberspace-independence

Barlow, J. P. (2000, February 25). The Debate Over Internet Governance: A Snapshot in the Year 2000 [Interview]. https://cyber.harvard.edu/is99/governance/barlow.html

Benkler, Y. (2006). The Wealth of Networks: How Social Production Transforms Markets and Freedom. Yale University Press.

Benkler, Y., Faris, R., \& Roberts, H. (2018). Network propaganda: Manipulation, disinformation, and radicalization in American politics. Oxford University Press.

Bennett, W. L., \& Pfetsch, B. (2018). Rethinking political communication in a time of disrupted public spheres. Journal of Communication, 68(2), 243-253. 
Bennett, W. L., \& Segerberg, A. (2013). The logic of connective action: Digital media and the personalization of contentious politics. Cambridge University Press.

Bimber, B. (2003). Information and American democracy: Technology in the evolution of political power. Cambridge University Press.

Bimber, B., \& Davis, R. (2003). Campaigning online: The Internet in US elections. Oxford University Press.

Bimber, B., \& Gil de Zúñiga, H. (forthcoming). The unedited public sphere. New Media \& Society.

Koc-Michalska, K., Bimber, B., Gomez, D., Jenkins, M., Boulianne, S. (2020). Public Beliefs about Falsehoods in News. The International Journal of Press/Politics, 25(3).

Boatright, R. G., Shaffer, T. J., Sobieraj, S., \& Young, D. G. (Eds.). (2019). A crisis of civility?: political discourse and its discontents. Routledge.

Boydstun, A. E., \& Lawrence, R. G. (2020). When Celebrity and Political Journalism Collide: Reporting Standards, Entertainment, and the Conundrum of Covering Donald Trump's 2016 Campaign. Perspectives on Politics, 18(1), 128-143.

Brock, A. (2012). From the Blackhand Side: Twitter as a Cultural Conversation. Journal of Broadcasting \& Electronic Media, 56(4), 529-549.

Golovchenko, Y., Buntain, C., Eady, G., Brown, M., Tucker, J. (2020). Cross-Platform State Propaganda: Russian Trolls on Twitter and YouTube During the 2016 US Presidential Election. The International Journal of Press/Politics, 25(3).

Bucy, E. P., \& D'Angelo, P. (2004). Democratic realism, neoconservatism, and the normative underpinnings of political communication research. Mass Communication \& Society, 7(1), 3-28.

Castells, M. (2007). Communication, power and counter-power in the network society. International journal of communication, 1(1), 29.

Chadwick, A. (2006). Internet politics: States, citizens, and new communication technologies. Oxford University Press.

Chadwick, A. (2009). Web 2.0: New Challenges for the Study of E-Democracy in an Era of Informational Exuberance. I/S: A Journal of Law and Policy for the Information Society, 5(1), 941.

Chadwick, A. (2019). The new crisis of public communication: Challenges and opportunities for future research on digital media and politics. Loughborough University, Online Civic Culture Centre. 
Chadwick, A., Vaccari, C., \& O'Loughlin, B. (2018). Do tabloids poison the well of social media? Explaining democratically dysfunctional news sharing. New Media \& Society, 20(11), 4255-4274.

Clark, D. (1992, July 13). A Cloudy Crystal Ball: Visions of the Future. 24th meeting of the Internet Engineering Task Force, Cambridge, MA.

Coleman, S., \& Blumler, J. G. (2009). The Internet and democratic citizenship: Theory, practice and policy. Cambridge University Press.

Deibert, R., Palfrey, J., Rohozinski, R., \& Zittrain, J. (2008). Access Denied: The Practice and Policy of Global Internet Filtering. MIT Press.

Deibert, R., Palfrey, J. G., Rohozinski, R., \& Zittrain, J. (2010). Access Controlled: The Shaping of Power, Rights, and Rule in Cyberspace. MIT Press.

Deibert, R., Palfrey, J., Rohozinski, R., \& Zittrain, J. (2011). Access Contested: Security, Identity, and Resistance in Asian Cyberspace. MIT Press.

Diamond, L., \& Plattner, M. F. (Eds.). (2012). Liberation Technology: Social Media and the Struggle for Democracy. Johns Hopkins University Press.

Dijk, J. A. G. M. van. (2005). The Deepening Divide: Inequality in the Information Society. SAGE Publications.

DiMaggio, P., Hargittai, E., Celeste, C., \& Shafer, S. (2004). From Unequal Access to Differentiated Use: A Literature Review and Agenda for Research on Digital Inequality. Social Inequality, 1, 355-400.

DiResta, R., Shaffer, K., Ruppel, B., Sullivan, D., Matney, R., Fox, R., Albright, J., \& Johnson, B. (2018). The Tactics and Tropes of the Internet Research Agency. /resources/thedisinformation-report/

Drezner, D., \& Farrell, H. (2004). Web of Influence. Foreign Policy, 145, 32.

Dunaway, J., \& Soroka, S. (2019). Smartphone-size screens constrain cognitive access to video news stories. Information, Communication \& Society, 1-16, DOI:

10.1080/1369118X.2019.1631367

Entman, R. M. (1990). Democracy without citizens: Media and the decay of American politics. Oxford University Press.

Erikson, R. S., MacKuen, M. B., \& Stimson, J. A. (2002). The macro polity. Cambridge University Press. 
Flynn, D. J., Nyhan, B., \& Reifler, J. (2017). The nature and origins of misperceptions:

Understanding false and unsupported beliefs about politics. Political Psychology, 38, 127-150.

Galloway, A. R. (2004). Protocol: How Control Exists After Decentralization. MIT Press.

Geiger, A. W. (2018, June 4). How Americans have viewed surveillance and privacy since Snowden leaks. Pew Research Center. https://www.pewresearch.org/fact-tank/2018/06/04/howamericans-have-viewed-government-surveillance-and-privacy-since-snowden-leaks/

Gibson, R. K., Nixon, P. G., \& Ward, S. J. (Eds.). (2003). Political parties and the Internet: net gain?. Routledge.

Giglietto, F., Iannelli, L., Valeriani, A., \& Rossi, L. (2019). 'Fake news' is the invention of a liar: How false information circulates within the hybrid news system. Current Sociology, 67(4), 625642.

Giglietto, F., Righetti, N., Rossi, L., \& Marino, G. (2020). It takes a village to manipulate the media: coordinated link sharing behavior during 2018 and 2019 Italian elections. Information, Communication \& Society, 1-25.

Goldsmith, J., \& Wu, T. (2006). Who Controls the Internet?: Illusions of a Borderless World. Oxford University Press.

Greenwald, G. (2013, June 6). NSA collecting phone records of millions of Verizon customers daily. The Guardian. https://www.theguardian.com/world/2013/jun/06/nsa-phone-recordsverizon-court-order

Guess, A., Nagler, J., \& Tucker, J. (2019). Less than you think: Prevalence and predictors of fake news dissemination on Facebook. Science advances, 5(1), eaau4586.

Gurevitch, M., \& Blumler, J. (1995). The crisis of public communication. Routledge.

Hacker, J. S., \& Pierson, P. (2010). Winner-take-all politics: How Washington made the rich richer--and turned its back on the middle class. Simon and Schuster.

Hargittai, E., \& Shaw, A. (2015). Mind the skills gap: the role of Internet know-how and gender in differentiated contributions to Wikipedia. Information, communication \& society, 18(4), 424442 .

Hedrick, A., Karpf, D., \& Kreiss, D. (2018). The earnest Internet vs. the ambivalent Internet. International Journal of Communication, 12, 8.

Hindman, M. (2005). The real lessons of Howard Dean: Reflections on the first digital campaign. Perspectives on Politics, 3(1), 121-128.

Hindman, M. (2008). The myth of digital democracy. Princeton University Press. 
Hindman, M. (2018). The Internet trap: How the digital economy builds monopolies and undermines democracy. Princeton University Press.

Howard, P. N. (2006). New media campaigns and the managed citizen. Cambridge University Press.

Howard, P. N. (2010). The digital origins of dictatorship and democracy: Information technology and political Islam. Oxford University Press.

Howard, P. N., Ganesh, B., Liotsiou, D., Kelly, J., \& Francois, C. (2018). The IRA and Political Polarization in the United States, 2012-2018. Computational Propaganda Research Project. https://comprop.oii.ox.ac.uk/research/ira-political-polarization/

Humprecht, E., Esser, F., \& Van Aelst, P. (2020). Resilience to Online Disinformation: A Framework for Cross-National Comparative Research. The International Journal of Press/Politics, 25(3).

Jamieson, K. H. (2018). Cyberwar: How Russian Hackers and Trolls Helped Elect a President: What We Don't, Can't, and Do Know. Oxford University Press.

Johnson, D. R., \& Post, D. G. (1996). Law and Borders-The Rise of Law in Cyberspace. Stanford Law Review, 48(5), 1367-1402.

Kalathil, S., \& Boas, T. C. (2010). Open Networks, Closed Regimes: The Impact of the Internet on Authoritarian Rule. Carnegie Endowment.

Karpf, D. (2019). On Digital Disinformation and Democratic Myths. Social Science Research Council MediaWell, retrieved from https://mediawell.ssrc.org/expert-reflections/on-digitaldisinformation-and-democratic-myths/

Liang, F., Das, V., Kostyuk, N., \& Hussain, M. M. (2018). Constructing a data-driven society: China's social credit system as a state surveillance infrastructure. Policy \& Internet, 10(4), 415453.

Lukito, J., Suk, J., Zhang, Y., Doroshenko, L., Kim, S. J., Su, M.-H., Xia, Y., Freelon, D., \& Wells, C. (2020). The Wolves in Sheep's Clothing: How Russia's Internet Research Agency Tweets Appeared in U.S. News as Vox Populi. The International Journal of Press/Politics, 25(2), 196-216.

Lupia, A., McCubbins, M. D., \& Arthur, L. (1998). The democratic dilemma: Can citizens learn what they need to know?. Cambridge University Press.

Lyons, B., Merola, V., Reifler, J., Stoeckel, F. (2020). How Politics Shape Views Toward FactChecking: Evidence from 6 European Countries. The International Journal of Press/Politics, 25(3). 
Lyon, D. (2015). Surveillance After Snowden. John Wiley \& Sons.

Mabry, E. A. (1997). Framing Flames: The structure of argumentative messages on the net. Journal of Computer-Mediated Communication, 2(4), JCMC241.

Margolis, M., \& Resnick, D. (2000). Politics as Usual: The Cyberspace “Revolution”. SAGE Publications.

Masullo Chen, G., Muddiman, A., Wilner, T., Pariser, E., \& Stroud, N. J. (2019). We should not get rid of incivility online. Social Media+ Society, 5(3), 2056305119862641.

McIlwain, C. D. (2019). Black Software: The Internet and Racial Justice, from the AfroNet to Black Lives Matter. Oxford University Press.

Morozov, E. (2012). The Net Delusion: The Dark Side of Internet Freedom. PublicAffairs.

Nash, V. (2019). Revise and resubmit? Reviewing the 2019 Online Harms White Paper. Journal of Media Law, 11(1), 18-27.

Negroponte, N. (1995). Being Digital. Knopf Doubleday Publishing Group.

Ng, E. W., \& Detenber, B. H. (2005). The impact of synchronicity and civility in online political discussions on perceptions and intentions to participate. Journal of Computer-Mediated Communication, 10(3), JCMC1033.

Norris, P. (2001). Digital Divide: Civic Engagement, Information Poverty, and the Internet Worldwide. Cambridge University Press.

Norris, P., \& Inglehart, R. (2019). Cultural backlash: Trump, Brexit, and authoritarian populism. Cambridge University Press.

Papacharissi, Z. (2002). The virtual sphere: The internet as a public sphere. New media \& society, 4(1), 9-27.

Papacharissi, Z. (2004). Democracy online: Civility, politeness, and the democratic potential of online political discussion groups. New media \& society, 6(2), 259-283.

Patterson, T. (1994). Out of Order: An incisive and boldly original critique of the news media's domination of America's political process. Vintage.

Pennycook, G., \& Rand, D. G. (2019). Lazy, not biased: Susceptibility to partisan fake news is better explained by lack of reasoning than by motivated reasoning. Cognition, 188, 39-50.

Phillips, W. (2015). This is why we can't have nice things: Mapping the relationship between online trolling and mainstream culture. MIT Press. 
Przeworski, A. (2019). Crises of democracy. Cambridge University Press.

Rheingold, H. (2002). Smart Mobs: The Next Social Revolution. Basic Books.

Roberts, M. E. (2018). Censored: distraction and diversion inside China's Great Firewall. Princeton University Press.

Robertson, C. T., Mourão, R. R., \& Thorson, E. (2020). Who Uses Fact-Checking Sites? The Impact of Demographics, Political Antecedents, and Media Use on Fact-Checking Site Awareness, Attitudes, and Behavior. The International Journal of Press/Politics, 25(2), 217237.

Rossini, P. (forthcoming). Beyond Incivility: Understanding Patterns of Uncivil and Intolerant Discourse in Online Political Talk. Communication Research.

Shapiro, A. L., \& Leone, R. C. (1999). The Control Revolution: How the Internet is Putting Individuals in Charge and Changing the World We Know. Perseus Books.

Shirky, C. (2009). Here comes everybody: How change happens when people come together. Penguin UK.

Sobieraj, S. (2019, October 22). Disinformation, Democracy, and the Social Costs of IdentityBased Attacks Online. MediaWell. https://mediawell.ssrc.org/expert-reflections/disinformationdemocracy-and-the-social-costs-of-identity-based-attacks-online/

Steele, C. (2017). Black Bloggers and Their Varied Publics: The Everyday Politics of Black Discourse Online. Television \& New Media, 19, 152747641770953.

Steele, C. K. (2016). The Digital Barbershop: Blogs and Online Oral Culture Within the African American Community. Social Media + Society, 1-10.

Surowiecki, J. (2004). The Wisdom of Crowds: Why the Many are Smarter Than the Few and how Collective Wisdom Shapes Business, Economies, Societies, and Nations. Doubleday.

Stier, S., Kirkizh, N., Froio, C., \& Schroeder, R. (2020). Populist Attitudes and Selective Exposure to Online News: A Cross-Country Analysis Combining Web Tracking and Surveys. The International Journal of Press/Politics, 25(3).

Stoycheff, E. (2020). Relatively Democratic: How Perceived Internet Interference Shapes Attitudes about Democracy. The International Journal of Press/Politics, 25(3).

Strömbäck, J. (2005). In search of a standard: Four models of democracy and their normative implications for journalism. Journalism studies, 6(3), 331-345. 
Tapscott, D., \& Williams, A. D. (2006). Wikinomics: How Mass Collaboration Changes Everything. Penguin.

Tenove, C. (2020). Protecting Democracy from Disinformation: Normative Threats and Policy Responses. The International Journal of Press/Politics, 25(3).

Tromble, R., \& McGregor, S. C. (2019). You Break It, You Buy It: The Naiveté of Social Engineering in Tech-And How to Fix It. Political Communication, 36(2), 324-332.

Tufekci, Z., \& Wilson, C. (2012). Social media and the decision to participate in political protest: Observations from Tahrir Square. Journal of communication, 62(2), 363-379.

Udupa, S., Gagliardone, I., Deem, A., \& Csuka, L. (2020). Field of Disinformation, Democratic Processes, and Conflict Prevention: A Scan of the Literature. Social Science Research Council. https://www.ssrc.org/publications/view/the-field-of-disinformation-democratic-processes-andconflict-prevention-a-scan-of-the-literature/

Vaccari, C. (2013). Digital politics in Western democracies: a comparative study. Johns Hopkins University Press.

Vaccari, C. (2019). Editorial. The International Journal of Press/Politics, 24(1), 3-6.

Vaccari, C., \& Chadwick, A. (2020). Deepfakes and Disinformation: Exploring the Impact of Synthetic Political Video on Deception, Uncertainty, and Trust in News. Social Media + Society, 6(1), 2056305120903408.

Vaidhyanathan, S. (2018). Antisocial media: How Facebook disconnects us and undermines democracy. Oxford University Press.

Waisbord, S. (2018). Truth is what happens to news: On journalism, fake news, and posttruth. Journalism studies, 19(13), 1866-1878.

Wells, C., Shah, D. V., Pevehouse, J. C., Yang, J., Pelled, A., Boehm, F., ... \& Schmidt, J. L. (2016). How Trump drove coverage to the nomination: Hybrid media campaigning. Political Communication, 33(4), 669-676.

Whitten-Woodring, J., Kleinberg, M., Thawnghmung, A., Thitsar, M.T. (2020). Poison if You Don't Know How to Use it: Facebook, Democracy and Human Rights in Myanmar. The International Journal of Press/Politics, 25(3).

Wolfsfeld, G., Segev, E., \& Sheafer, T. (2013). Social media and the Arab Spring: Politics comes first. The International Journal of Press/Politics, 18(2), 115-137.

Wu, T. (2017). The attention merchants: The epic scramble to get inside our heads. Vintage. 
Zhang, Y., Wells, C., Wang, S., \& Rohe, K. (2018). Attention and amplification in the hybrid media system: The composition and activity of Donald Trump's Twitter following during the 2016 presidential election. New Media \& Society, 20(9), 3161-3182.

Zuboff, S. (2019). The age of surveillance capitalism: The fight for a human future at the new frontier of power. Profile Books. 